\title{
Infância, higiene e saúde na propaganda (usos e abusos nos anos 30 a 50)
}

Olga Brites

Pontifícia Universidade Católica de São Paulo

\section{RESUMO}

Este artigo discute imagens da infância construídas na propaganda brasileira, destacando os temas de higiene e saúde, presentes nos mais diferentes produtos: eletrodomésticos, móveis, remédios, alimentos, iluminação, etc. As imagens de infância veiculadas estavam associadas à família, apresentando a criança como dependente do adulto. Além do consumo, a propaganda é debatida em seus vínculos com experiência cultural e espaço público.

Palavras-Chave: Infância; Propaganda; Família; Saúde; Higiene.

\begin{abstract}
This article discusses childhood images built into Brazilian propaganda. It emphasizes subjects as hygiene and health and analyses their presence in advertisements of food, household equipaments, enlightenment, furniture, medicaments, etc. Childhood images transmited through these advertisements linked to family. Children appeared as dependent on adults. Propaganda is debated in this article from some points of view as consumption, cultural experience and public space. Key-Words: Childhood; Propaganda; Family; Health; Hygiene.
\end{abstract}




\section{Consumir é viver}

Conviver é sumir

(Paulinho da Viola e Marcus

Vinícius de Andrade, Consumir é Viver)

Esses versos de Marcus Vinícius de Andrade, musicados por Paulinho da Viola, apresentam o horizonte do consumo como expressão de vida e, ao mesmo tempo, exterminador de convívios, da própria vida. Daí as relações de mercado aparecerem como única perspectiva de sociabilidade existente, eliminando por completo outras dimensões de convívio entre as pessoas. Seu irônico jogo de palavras conduz parodicamente à inversão dos significados explícitos e à conclusão de que o consumo faz sumir e que viver está no convívio.

São versos do final dos anos 60, marcados pelo universo dos hip pies, da Contra-cultura, dos combates à ditadura no Brasil e das críticas ao consumismo nas so ciedades industriais ${ }^{1}$. Sua dimensão crítica inspira a reflexão sobre como o mundo da propaganda, ao se impor momentos históricos, modificou estilos de vida e comportamentos, ao mesmo em outros tempos em que foi elaborado a partir de hábitos e costumes da população, como se verifica em imagens da infância veiculadas pela propaganda impressa no Brasil dos anos 30 a 50 .

"As crianças são o sorriso de Deus na terra. Mas, uma criança só é feliz, bem cuidada, e só é bem cuidada com talco Lady, um produto de pureza absoluta”2. Esse argumento evoca uma dimensão divinizada da infância, vestígio de Deus na Terra, associando a felicidade diretamente ao sagrado. A pureza do produto, conseqüentemente, foi aproximada da criança e de Deus, justificativa para aquisição e uso. O paralelismo entre esses universos de pureza teve por desfecho o incentivo ao consumo, evidenciando que a criança fez parte tematicamente da propaganda, assim como essa produção publicitária participou de sua formação e da construção de imagens de infância. Ela era, portanto, destinatária (através dos adultos), assunto e justificativa de parte do material publicitáno disponível no Brasil naquele período. Os anúncios na imprensa brasileira dos anos 30 a 50 desdobravam-se em diferentes gêneros - os classificados, os tipográficos, próximos de editoriais, os ilustrados com diferentes tipos de gravuras e fotografias. Ramos acrescenta àqueles tipos de anúncios as diferenças de "tamanhos e disposições (...) de página, de meia, um terço, um quarto ou menos, os espelhados com matéria rediconal ou intercala- 
dos, os horizontais, rodapés, negativos, os centrais reduzidos ou axadrezados" ${ }^{\prime 3}$.

As revistas O Cruzeiro e Manchete, importantes semanários brasileiros desse período e fartamente ocupadas por materiais publicitários, tinham como público-alvo as camadas médias da população, veiculando anúncios de produtos e serviços. O Cruzeiro, surgida nos anos 20, atingia frações de renda mais baixa daquelas camadas, como se verifica nos anúncios de cursos técnicos e nas pesquisas de mercado dos anos 50 e 60. Manchete, lançada na década de 50, diferenciava-se por evitar um tom sensacionalista mais próprio à outra publicação, explorando um estilo que pretendia ser sóbrio e ponderado, calcado no modelo francês do semanário Paris-Match ${ }^{4}$.

Nos anos 50, segundo Figueiredo, ficou evidente a formação de um mercado de consumo de bens industriais no Brasil que não se restringia a minorias privilegiadas, abrangendo setores populares, o que se manifestava no plano da propaganda pela inclusão ou ampliação da presença de personagens como crianças e idosos. O noticiário desses periódicos como, de resto, na grande imprensa brasileira em geral - era muito influenciado pelo capital publicitário na medida em que este tinha grande importância na manutenção financeira das publicações. Ao mesmo tempo, o consumo almejado abrangia tanto os produtos indicados como a própria mercadoria periódico, fortalecendo um contexto geral de consumo. Para o autor, essa publicidade construiu ao longo dos anos certo espaço público que, cada vez mais, interferiu na vida privada, atribuindo aos objetos qualidades afetivas que lhes davam vida, característica que encontrava ressonância no social. Diante da impessoalidade própria à sociedade urbana e industrial, em que a população tinha (e tem) pouco convívio direto, a publicidade funcionava (e funciona) como patamar de identificação e diferenciação. O consumo de determinados produtos, nesse contexto, passou a significar índice de prestígio, diferenciando, também sugerindo a universalização de sua possibilidade.

A propaganda, ao mesmo tempo que se articulava com problemas gerais de políticas públicas, cultura e periodismo - questões como censura, incentivos temáticos, projetos gerais, possibilidades técnicas e comerciais da produção -, manteve um projeto próprio no que se referia ao universo do consumo, percorrendo questões de saúde, alimentação, vestimenta, beleza, modernidade, louvor do mundo industrial, sob o signo do consumo como solução universal para todos os males. Esse consumo possuia ainda uma face, talvez inconsciente e involuntária, de direito ao 
prazer, acenando com a possibilidade de diferentes camadas sociais tomarem conhecimento de bens e serviços, ansiando pelo acesso ao seu mundo. $\mathrm{O}$ vínculo entre criança, mãe e família foi intensamente alimentado no mundo da publicidade brasileira dos anos 30 a 50, servindo de mote para a apresentação e a justificativa dos mais diversos produtos.

A propaganda não estava alheia às discussões que oco rriam sobre a infância em diferentes espaços do governo e da sociedade civil, até contribuia no sentido de forjar imagens ideais de criança, assumindo em diversos momentos um tom mais leve de trabalhar temas. Por meio do humor, ela construia estratégias de convencimento da população, como se observa em anúncio de Lysoform, divulgado em 22 de janeiro de 1935 no jornal O Estado de São Paulo. Nele, a parteira foi reconhecida como autoridade no momento do nascimento, demonstrando sua presença significativa nos campos de Saúde e Higiene. Na verdade, o Lysoform foi também indicado noutras ocasiões para homens usarem depois de se barbearem, para fumantes fazerem gargarejos, para limpeza de geladeira e despensa, a fim de acabar com percevejos e pulgas e, no caso do bebê, para desodorisar suas roupas. Aconselhou-se ainda o uso de embalagem grande que rendia mais e era econômica. A grandiosidade do produto foi 252 assim destacada: "Lysoform é como o corcovado! não há outro. Acima dele só o Cristo e imitação não presta". O texto sugeriu que havia outros produtos no mercado tentando se assemelhar àquele. O apelo ao Corcovado serviu como índice de monumentalidade, patrimônio da cidade: assim como aquele lugar era referência fundamental para os moradores do Rio de Janeiro, o produto o era para as famílias; por outro lado, o Corcovado representava um símbolo sagrado, portanto inquestionável, tal como Lysoform devia ser. Houve um forte apelo a símbolos, imagens, crenças, sendo a criança sacralizada, comparada a anjinho querido, um ser que e devia preservar, venerar.

Noutra propaganda, houve apelo aos adultos para que pensassem pelas crianças, apresentando desenho de três garotos brincando com trenzinho. O brinquedo aqui foi caracterizado como algo que alienava para a vida, não exigia pensamento. $\mathrm{O}$ pai que pensasse pelo filho garantiria para ele um futuro tranqüilo, sem problemas. Para isso, o Plano de Seguros Sul América seria eficaz, apontando diversas formas de pagamento como elemento positivo na sua aquisição. O seguro foi ainda apresentado como garantindo felicidade e tornando a criança notável: "Ainda não lês e já estão garantidos os meios de te fazeres um homem notável"s. A propaganda aqui mexeu com um valor julgado fundamental, o da leitura, colo- 
cando no produto uma profunda eficácia para sustentar um futuro feliz. Ler era muito importante para qualquer pessoa tomar-se autônoma e responsável por seu destino mas enquanto isso não ocorresse, possuir o Seguro Sul América já constituía uma garantia.

A orfandade, tema tão freqüente em revistas e diferentes vozes do governo e da sociedade civil daquele perío do, apelando para a compaixão em relação a crianças sem pais, que viviam em abrigos, desprotegidas de assistência material e espiritual, necessitando da generosidade de adultos estranhos para terem mínimas condições de existência digna, foi transformada na propaganda que tratava de seguros de vida, em que os pequenos apareceram ao lado da mãe, felizes porque assistidos por aquela garantia. A situação de possível desamparo e sofrimento, portanto, seria afastada mediante apelo àquele produto

O mundo da pobreza e das etnias não-brancas esteve pouco presente na propaganda brasileira desse perío do, exceto como signo do que se devia corrigir (deixar de ser pobre, alcançar sucesso), na identificação com a cor de produtos (café e chocolate, por exemplo) e em contextos de fantasia (crianças vestidas como índios). A cidade industrial funcionou como tecido principal das experiências apresentadas, que podiam ser deslocadas também para o campo, em nome de uma vida mais confortável e moderna.

1930 não foi inaugural no que se referia a imagens de infância na publicidade brasileira. Alguns produtos - leite condensado e leite em pó, por exemplo - já estavam consolidando-se no mercado do país desde 0 início do século XX e ampliaram ainda mais seu círculo de influências nos anos 30 a 50.

Se houve nesse período uma postura médica de combate aos curandeiros, ela também se fez presente quando se tratava de propagandas de remédios e produtos similares, condenadas por profissionais de Saúde na medida em que fomentavam a auto-medicação e dispensavam a consulta, transformando rádio e bondes em "consultórios médicos clandestinos" ${ }^{\prime}$. Os médicos admitiam propagandas elaboradas para seus pares, veiculadas em periódicos especializados ou como folhetos e materiais similares dirigidos àqueles profissionais, assinalando a diferença que observavam entre produtos nacionais, anunciados em via pública, rádios e outros veículos semelhantes, e os estrangeiros, que percorriam aquele circuito da especialização. Isso não impediu o grande sucesso popular no Brasil de anúncios de remédios, incluindo clássicos do gênero, como os jingles de "Pílulas de Vida do Dr. Ross", segundo Temporão. Ao mes- 
mo tempo, para Figueiredo, as peças publicitárias asso ciavam os interesses do capital nacional e do capital internacional.

Essa postura médica não serviu de barreira a propagandas de matemidades, consultórios, laboratórios de análises clínicas, médicos especialistas e outras instâncias desse campo de saber, numa escala editorial menor que a das grandes empresas, na forma freqüente de "tijolinhos" (pequenos anúncios, reduzidos a poucas informações - endereço, nome, etc.). Ao mesmo tempo, o médico apareceu em publicidades de múltiplos ítens de consumo como autoridade, demonstrando uma aliança entre a propaganda e tal profissional e figurando mesmo em determinados anúncios como chancela individualizada, que indicava o nome do profissional junto com nome e endereço da criança por ele atendida e que dele recebera a recomendação do produto. Certas peças publicitárias, como ocorreu em Vida Doméstica em janeiro de 1941 até mencionaram que seus objetos eram aconselhados por médicos do mundo todo, dupla legitimação pelo profissional e pelo universo. Outra estratégia paralela a essa foi recomendar o produto anunciado e sugerir a ida ao médico, garantindo que ele também o indicaria. Em contraponto às reservas médicas, algumas propagandas valorizaram o conselho de amigas no uso de determinados produtos. Foi o caso do Vinho Reconstituinte Silva Araújo, em cuja publicidade figuraram tanto o conselho da amiga como a indicação do médico, vozes que funcionaram harmonicamente. Em declaração atribuída a uma telefonista do Rio de Janeiro, Vida Doméstica de abril de 1939 afirmava: "Era uma pilha de nervos! Além de fraca, eu estava nervosíssima. Cada semana, era um novo remédio e eu sempre na mesma. Afinal, por insistência de minha amiga, comecei a tomar o Vinho Reconstituinte Silva Araújo. Foi uma salvação!”. Esse procedimento textual apoiou-se na referência a personagem supostamente real, garantindo maior confiabilidade ao produto.

A presença de médicos como personalidades públicas em propaganda se relacionou com o fortalecimento de sua atuação na cena social, tanto cuidando de corpos como atingindo mesmo o universo das almas, afastando (ou, ao menos, dividindo vantajosamente a cena com) benzedores, curandeiros, padres ${ }^{7}$. O utra dimensão dessa propaganda era perpetuar imagens da criança ideal. Nesse sentido, ela fazia parte de um poder que se construia e desejava falar sobre mulheres, homens e crianças. Ao elaborar a imagem do futuro cidadão como saudável, forte e robusto, tentava-se romper com um presente vivido principalmente pelas crianças pobres, em especial o da fragilidade e da ausência de higiene e sucesso, 
destruindo uma imagem que não se queria cristalizar como memória. Assim procedendo, deixava-se de considerar experiências significativas do presente e do passado, expressas em tradições culturais, como se essas diferentes temporalidades não fossem marcadas por tensões, conflitos e importantes construções sociais ${ }^{8}$.

Muitas peças publicitárias produzidas no Rio de Janeiro durante 0 período considerado alcançaram circulação nacional. Também noutras cidades brasileiras - com destaque para São Paulo, em grande expansão urbana e industrial naquelas décadas -, foram elaborados materiais similares, que circularam além de um espaço local ${ }^{9}$. O crescimento paulistano possuía uma dimensão cosmopolita, lançando produtos no mercado nacional (e mesmo estrangeiro), bem como recebendo-os dessas diversas fontes. Daí, a razão de, ao abordar a propaganda e falar de São Paulo e Rio de Janeiro, trabalhar-se com faces de imagens da infância em todo o Brasil e mesmo noutras partes do mundo.

Apesar disso, também havia modalidades de divulgação publicitária com forte impacto na paisagem de cada cidade. A popularidade do Biotônico Fontoura, por exemplo., não resultou somente de anúncios em grandes revistas, rádio e, depois, televisão. Existiu anúncio luminoso, registrado em fotografia de 1943, que estava instalado em prédio da cidade de São Paulo, numa de suas regiões de maior circulação à época: a parte alta da Avenida São João, em frente ao Edifício Martinelli. Um anúncio de Café e Açúcar União, por sua vez, expunha duas crianças de costas: uma menina negra e um garo to branco. Incluía, ainda, o símbolo do produto - duas mãos dando-se. A propaganda era veiculada em bondes que circulavam pela cidade. Apelar para crianças de sexos e cores diferentes significou remeter para idéias de união e totalidade, união entre homem e mulher, café preto e açúcar branco como elementos complementares, e, através da faixa etária escolhida, para a idéia de fraternidade assexuada. Os exemplos de Biotônico Fontoura e Café e Açúcar União misturavamse à paisagem urbana de São Paulo, como se crescessem e se movimentassem junto com a cidade. Nessa dinâmica, a infância apareceu na condição de suporte argumentativo a favor do produto (Café e Açúcar União) e também como participante da cidade que crescia junto com ela, evocando valores positivos como união e solidariedade, junto com sua própria condição etária, anúncio de um futuro harmonioso, que representava um rompimento em relação ao passado de possíveis problemas mortalidade infantil, ignorância, conflitos.

As imagens visuais não eram tratadas na propaganda como meras 
substituiçõ es da palavra escrita, uma vez que representavam uma cultura do olhar, que educava no sentido do consumo, da admiração da riqueza, da modernidade como espetáculo. A ilustração, portanto, não se constituia em simples confirmadora da mensagem verbal, representando uma outra leitura que queria atingir a população. Daí, edifícios, bondes e demais suportes poderem ser entendidos como propagadores dessa nova leitura, mediante cartazes, out-doors e imagens diversas, integrando a constituição do social. Nas propagandas, textos e ícones eram linguagens diferentes, que se complementavam para transmitir suas mensagens, num diálogo entre a visualidade e o verbal.

Os anos 40 e 50 foram o período de auge da revista 0 Cruzeiro, que veiculou uma série de imagens da infância, bem como do surgimento do semanário Manchete (última década), concorrendo com o anterior, e do início da televisão no país. O Cruzeiro caracterizou-se por se dirigir ao consumo da própria família, com uma série de artigos e seções que colocavam problemas a ela referentes, apresentando conselhos para as mulheres em seções especiais sobre assuntos designados como femininos figurinos, receitas culinárias, sugestões para decoração, etc. Além disso, introduziu no Brasil, a partir dos anos 40, um modelo de revista com grandes reportagens fotográficas. Manchete ficava mais restrita ao campo das fotografias, menos voltada para o modelo familiar ${ }^{10}$. A propaganda, nesse contexto, apareceu como mito da vida moderna, apresentando-se enquanto solução mágica para tudo, com os produtos veiculados trazendo alegria, felicidade, sucesso, sendo a família - inclusive a criança - realizadora desse projeto porque consumidora.

Nos anos 50, a publicidade ainda usava textos longos para transmitir suas mensagens, o que suscitou debates entre profissionais dos meios de comunicação, denunciando o excesso de anúncios e, neles, a extensa parte escrita. Se os anúncios eram fundamentais em Vida Doméstica, por exemplo., a revista também publicou em janeiro de 1928 reportagem condenando o excesso de reclames nas rádios - mas não nas publicações - , que poderiam perder audiência devido à exaustão causada pelas propaganda. Apesar disso, o textual na publicidade foi fundamental, mesmo que reduzido, porque participava intensamente das mensagens veiculadas. Essa questão remete ao universo da cultura letrada na cidade, que abrangia diferentes suportes - imprensa, propaganda, cartazes, etc. -, com a linguagem da publicidade marcando espaços das mais diferentes formas em periódicos, folhetos, grande imprensa, popularizando-se, criando novos mercados, patrocinando edições ${ }^{11}$. 
Nesse contexto, a propaganda sofreu certa rejeição pela cultura letrada (principalmente, das revistas acadêmicas), que se negava inicialmente a ver tal produção como séria. Assim, o espaço reservado à publicidade na imprensa começou pequeno no século XIX. Com o crescimento da cidade e de seu comércio, principalmente a partir das últimas décadas do século XIX, surgiram anúncios de rua e transportes como bonde, onde os passageiros ocupavam os olhares com reclames, tema presente em lembranças de moradores da cidade, começando a popularização dessa linguagem e da imprensa, que atingiam diferentes grupos sociais. Esse material trouxe novos códigos de leitura e o mercado de anúncios se ampliou, sofisticando a linguagem, utilizando charges, desenhos e fotos, com homens de letras assumindo tal espaço como possibilidade de trabalho, tendência que já se observava no Rio de Janeiro desde os anos 10 do século $\mathrm{XX}^{12}$.

Os anos 50 representaram período significativo no crescimento da publicidade brasileira em diferentes veículos, diferenciando-se em termos da linguagem visual à medida que foi ampliada a exploração de recursos como fotografia e cor. Os anúncios ainda não tinham a criança como público preferencial. Elas apareceram tematicamente e, de forma indireta, enquanto consumidoras, com muitos produtos procurando atingir to da a família, associados a diversas gerações. A criança preferida como personagem ou referência publicitária em revistas, logicamente, era aquela cuja família tinha acesso ao consumo. A indústria alimentícia também marcava sua presença na publicidade, descrevendo seus produtos como ricos em vitaminas e adequados para colaborar com a infância saudável e uma família feliz. Esse tema da saúde na infância foi recorrente na propaganda do período, como em outras instâncias sociais, valorizando a robustez infantil como sinônimo de vida saudável. As publicidades em jornais e revistas anunciavam uma série de produtos destinados à formação do corpo forte como elemento fundamental do ser criança, em especial, remédios e alimentos. A indicação do leite para a criança foi uma constante, absorvendo a discussão sobre a importância do aleitamento materno. Alguns produtos anunciados revelavam-se apropriados para as crianças privadas daquele tipo de alimento, destacando seu valor nutritivo ou ainda, em alguns casos, com o argumento de que o artigo industrializado lembrava o "puńssimo leite de vaca", demonstrando que o leite animal já era assimilado como produto de boa qualidade ${ }^{13}$.

A oralidade apareceu indiretamente nos anúncios impressos através de conversa com o público leitor, sugerindo a compra de determinados produtos ou ainda utilizando diálogo entre personagens que expressa- 
vam sentimentos de admiração, alegria e surpresa, dentre outros. Reproduzir situações vividas no cotidiano das relações entre adultos e crianças, homens e mulheres, configurava poder de convencimento sobre o público consumidor. Temporão salientou o caráter extensamente informativo de publicidades impressas na segunda década do século XX.

Foi em 1950 que se inaugurou, em São Paulo, a TV Tupi. Nessa época e durante muitos anos, existiram comerciais de televisão ao vivo. Segundo Ramos, a Escola Superior de Propaganda e Marketing, por sua vez, foi fundada em São Paulo no ano seguinte, demonstrando a crescente importância da área e a necessidade de formar profissionais que a ela se dedicassem a partir de novas bases. Essa foi também uma fase de popularização dos eletrodomésticos e industrialização de múltiplos produtos destinados ao consumo familiar, tendência que se configurava desde a década anterior ${ }^{14}$.

A ampliação do mercado consumidor brasileiro nos anos 50 criou também novas técnicas de venda, mais promoções e o crediário se expandiu, colocando para as empresas necessidades de incrementar a publicidade. Nesse mesmo período, surgiram chamadas constantes de pé de página na revista Vida Doméstica para instituir o uso do cheque no 258 Brasil como elemento de progresso. Isso sugere grande capacidade instituinte da propaganda e da imprensa na introdução de novos serviços ou produtos. Exemplo paralelo pode ser citado na revista O Cruzeiro dos anos 40: propaganda de máquina de lavar aconselhava a dona-de-casa a comprar barra de sabão e ralá-la para preparar o molho da lavagem, evidenciando a inexistência ou insuficiência no mercado brasileiro de sabão em pó e a força da publicidade na implantação do uso daquele eletrodoméstico.

Tratava-se, ainda, de período marcado pelo crescimento industrial brasileiro em ramos como a indústria automobilística, que tinha um peso fundamental na medida em que incentivava a expansão de outros setores industriais que lhe eram complementares - auto-peças, acessórios, etc. Nas duas décadas anteriores, políticas públicas enfatizaram a implementação de bases, no Brasil, para o que se considerava uma sociedade moderna, urbana e industrial, o que incluía tanto o apoio a atividades econômicas nesses espaços como legislação que servia de argumento para demonstrar novas atitudes governamentais e empresariais em relação ao trabalho e controle sobre a livre organização e manifestação de setores da sociedade. A valorização do moderno se deu, no Brasil, ao menos desde os anos 20, explicitamente nas áreas artísticas mas também em cam- 
pos sócio-culturais muito diversificados, da Educação à Pesquisa Científica e Tecnológica, abrangendo argumentos de racionalização do social ${ }^{15}$. A propaganda existiu articulada, portanto, a um setor industrial que se expandia e investia no crescimento de seu mercado, construindo o espetáculo da produção e do consumo sem limites.

O material publicitário brasileiro daquele período atesta a importância da indústria alimentícia como anunciante. As propagandas em que a criança apareceu como alvo e justificativa do consumo colocavam a alimentação enquanto fonte de saúde, destacando crescimento e robustez como elementos fundamentais para a infância. A Farinha Láctea Nestlé, por exemplo, destacava praticidade no preparo da comida, economia de tempo e dinheiro e seu caráter de alimento rico em vitaminas, que garantia crescimento saudável para as crianças. Reclame de 1909 trouxe em seus dizeres: "Sempre foi e ainda é o alimento mais poderoso e mais nutritivo para crianças e convalescentes" ${ }^{16}$, construindo imagem de teor nutritivo tão elevado a ponto de funcionar como remédio ${ }^{17}$. Noutro anúncio de 1917, figurou desenho de menina com dedo da mão direita na boca, segurando boneca com a mão esquerda; situada no centro do quadro e com uma embalagem do produto de cada lado de seu corpo; acima dessa imagem, como primeira chamada da propaganda os dizeres: "Não me falem de política"; abaixo, num quadrado, argumentou-se: "Mas vejão que não falte para mim e para minha boneca a Farinha Láctea Nestlé. Gosto tanto della, e me dou tão bem...Com o emprego da Farinha Láctea Nestlé criarse-hão meninos sadios e bem desenvolvidos. À venda em toda parte" ${ }^{18}$.

O anúncio explorou certa oralidade ao ser escrito no estilo de uma conversa: hipoteticamente, foi a criança que recomendou ao adulto os cuidados que sua condição infantil merecia; gostar e se dar bem com 0 produto foram atributos para compra que a própria menina indicou. Ocorreu a dimensão da brincadeira, própria ao universo infantil, que precisava ser respeitada pelo adulto; brincar era estar saudável; em contrapartida, criar crianças fortes era condição fundamental que o adulto precisava assumir. O próprio desenho da menina lembrava também imagem de boneca, através de roupas, chapéu, pernas, sapatos, como se a criança e seu brinquedo tivessem identidades extremamente próximas - mãe e filha ou duas bonecas, por exemplo. No entanto, quando se fala de publicidade, a consideração de várias temporalidades é necessária para a avaliação das especificidades na constituição daquela linguagem e a reflexão acerca de algumas de suas redefinições, articuladas a outras experiências da socie- 
dade: nem sempre a propaganda desse tipo de produto se apoiou na imagem de criança.

Em outro anúncio de 1919, por exemplo., um desenho apresentou dois homens: um situado em plano maior, forte e musculoso, com os pei torais destacados, de lado para público leitor, descalço, usando shorts e sem camisa; o outro, em frente daquele, também de lado para público leitor, caracterizado como baixo, usando casaca, calças, sapatos e óculos, tendo corpo raquítico se comparado ao primeiro. Toda essa vestimenta escondeu seu físico, ao contrário do outro personagem, caracterizado como saudável esportista. A sofisticação dos trajes não apareceu como atributo positivo na medida em que era preciso expor o físico ${ }^{19}$. Os únicos escritos foram registrados acima do desenho, contendo o nome do produto, Farinha Láctea Nestlé, e a legenda: "Força e Vigor". A imagem mereceu mais investimentos de significações que o texto; o homem alto exibiu os atributos supostamente oferecidos pelo produto, numa iconografia masculina onde força e vigor foram expressos através de músculos, altura, sugerindo-se que toda criança alimentada com o artigo adquiriria as qualidades físicas ali expostas. Esse anúncio também assumiu que o produto não era dirigido apenas ao consumo infantil, afirmando-se como 260 parte da força adulta. Ocorreu uma imagem oculta da criança como destinatária e pré-figuração daqueles futuros possíveis - força ou debilidade.

Há outro reclame, de 1928, que se dirigiu diretamente às mães, responsabilizadas pela saúde das crianças. Um desenho apresentou mulher usando avental e salto alto, com um prato quente nas mãos, dirigindo-se ao filho pequeno, que lhe estendia os braços; ao lado do garoto, também olhando para a mãe, apareceu uma menina segurando com a mão esquerda uma boneca; junto deles, estava a embalagem daquele produto, com o texto que dizia: "A alegria no lar depende da saúde das crianças. Mães empreguem a boa Farinha Láctea Nestlé que contém todos os alimentos necessários ao desenvolvimento normal de seus filhinhos. Dirijam-se à Cia Nestlé Caixa Postal 760 Rio. Que lhes enviará gratuitamente amostras e brochuras!"20. Um único alimento continha, de acordo com o anúncio, vários, o que facilitava a vida no lar, garantindo saúde e felicidade da família. Nesses termos, ele apareceu como fator de economia e alta rentabilidade e a empresa se ofereceu enquanto ponto de apoio para o máximo aproveitamento dessas possibilidades. Papéis tradicionais da mulher (mãe, cuidando dos filhos, zelosa, generosa) e da criança (na família, bem estruturada socialmente) foram repostos, situaçõ es sintonizadas com discursos médicos, jurídicos, governamentais e de imprensa do período. Ao 
mesmo tempo, valorizou-se a dimensão de novo tempo, de que fazia parte o ser dona-de-casa que, graças àquele aparato técnico disponível, tinha acesso a uma qualidade de vida superior e diferente, oferecida pela indústria e pela propaganda.

Cerca de duas décadas depois, um anúncio de 1955 apresentou, em primeiro plano, um prato contendo o produto, com mão feminina mexendo os ingredientes da vasilha; em plano mais afastado, figurou uma seqüência em três quadros, que ensinava as mulheres a prepará-lo adequadamente. Um texto abordou a rapidez de se fazer o alimento e outro, em menor destaque, salientou seu valor nutritivo, rico em vitaminas. 0 anúncio recomendou a Farinha Láctea Nestlé para crianças de mais de 6 meses, escolares, mulheres que amamentavam, convalescentes e todos que precisavam de refeições com alto valor nutritivo. Além das dimensões de economia e potencial remédio (indicado para convalescentes), esse exemplo salientou a praticidade e a rapidez no preparo, sugerindo a crescente importância de tempo e velocidade entre os valores sociais então vigentes, sem perder aqueles outros, consolidados há décadas na memória de seu consumo. O produto apareceu como garantia de maior eficiência e produtividade, conciliando o trabalho feminino em espaços domésticos e públicos ${ }^{21}$.

Outra propaganda do mesmo produto, de 1961, usou como recurso narrativo a fotografia, inovador em relação aos anúncios trabalhados até então. Há um menino sorridente, sentado em cadeira de bebê, de frente para a mesa, coberta por uma toalha e com um prato sobre ela. A vasilha estava vazia e o menino, com a mão direita, segurava a colher dentro do prato; seu rosto expressava alegria. Um balão com texto registrou: "não sobrou nada”22. Também aqui a oralidade esteve presente: a criança falou, adquirindo certa autonomia que conferiu prestígio à mercadoria. Abaixo da cena, textos mais longos ensinavam a preparar o produto, afirmando que ele facilitava a digestão. Ofereceram-se, no anúncio, outras opções de alimentos que podiam ser feitos com o artigo, como refrescos e bananas amassadas.

Nessa série apresentada, alguns elementos se mantiveram, ao longo dos anos, como atrativo para a compra da Farinha Láctea Nestlé: saúde, beleza, força e felicidade foram valores que pareceram atemporais, mudavam estratégias de anúncio e sofisticação técnica - cores, fotografias, novos recursos gráficos - , construindo mais possibilidades de consumo, sugerindo receitas que permitiam variar o uso do alimento - além das já indicadas vitaminas e mingaus. Ela também explorava o prazer e o gosto 
das crianças pelo produto, sugerindo sabor agradável. A propaganda valorizou certos alimentos, associando-se indiretamente a campanhas institucionais (SESI, governo federal, etc.). As famílias mais pobres, por sua vez, traduziam e criavam valores em relação a esse assunto, adotando também estratégias de convencimento para seus próprios membros. Guardo lembranças de infância (anos 50) de minha mãe procurando convencer-me e a meus irmãos a consumir alguns produtos, destacando a importância nutritiva de pão, fubá e leite, dentre outros, o que demonstra o alcance daquelas campanhas junto à família.

A própria Nestlé realizava concursos de Puericultura e Pediatria para profissionais de Saúde, no sentido de estimular produções acadêmicas, referentes à saúde infantil. No ano de 1953, publicou "Estudos so bre a proteção do recém-nascido contra o tétano umbilical pela imunização ativa da gestante em Anatoxina Tetânica". Não é o caso de se discutir esse estudo em suas especificidades médicas, mas o texto de apresentação assinado pela Nestlé é significativo para se perceber como essa empresa, enquanto indústria alimentícia, dizia-se aliada à Ciência no combate aos problemas infantis, ao mesmo tempo em que reafirmava seu caráter de seriedade e compromisso real com profissionais da saúde no atendimen262 to à população: "A presente publicação é um reflexo da magnitude de uma colaboração preciosa a custa da qual se faz o progresso visível da civilização: a colaboração entre a ciência e a indústria, estimulando a investigação nos mais variados campos científicos para o enriquecimento da cultura e melhoria do nível de vida da humanidade". A instituição do "Prêmio Nestlé de Pediatria e Puericultura" bem demonstra o desejo de que tem sido sempre imbuída a Organização Nestlé para a realização deste largo ideal, fomentando e divulgando estudos relativos à Pediatria e à Nutrição, apoiada por suas tradicionais relações com a Classe Médica.

Com o intuito de divulgar as mais recentes pesquisas no campo da medicina infantil, apresentamos neste volume o trabalho que mereceu o primeiro lugar de tema livre e que se reveste de maior valor quando verificamos que êste estudo já havia sido sugerido pela Organização Mundial de Saúde. É, pois, com satisfação que, mais uma vez, oferecemos aos nossos leitores a divulgação de trabalho de real interêsse, continuando no nosso firme propósito de bem servir à Pediatria brasileira. Companhia Industrial e Comercial Brasileira de Produtos Alimentícios Nestlé23.

A participação da Nestlé em campanhas, eventos ou atividades go vernamentais, científicos e outros era também forma de propaganda da 
marca, consolidando-a junto a diferentes públicos. Cabe considerar o interesse das indústrias alimentícias em criar necessidades de seus produtos no mercado e investir na propaganda. A própria Nestlé, desde o início do século XX, vendia farinha láctea e leite condensado em Pernambuco, Bahia, Santos e Rio de Janeiro. Em 1910 e 1912, houve crescimento do mercado para Amazonas e Pará. Por meio daquela promoção editorial, emergiu a valorização de alimentos industriais, associada ao mundo científico e aos interesses dos consumidores, no contexto de uma nova economia do cotidiano que dedicava menos tempo social para o preparo doméstico de alimentos. Logo após a Segunda Guerra Mundial, houve vendagem significativa dos leites artificiais, com a década de 50 representando os "anos dourados" nessa direção, simultaneamente ao crescimento substantivo da população infantil. Fazia parte das estratégias de marketing das indústrias alimentícias para a expansão da demanda de seus produtos ter os profissionais da saúde como aliados. Os médicos, por sua vez, aceitavam participar do incremento ao consumo desses produtos como forma de controle sobre seus pacientes, que passariam a procurá-los com mais freqüência, dependendo de suas orientações.

Os rótulos desses artigos foram interpretados como incentivo ao seu uso por mulheres pobres e analfabetas do terceiro mundo, com a embalagem como força de sedução para o consumo. Os Programas de Suplementação Alimentar (PSA), que tiveram início no Brasil nos anos 40, pretendiam chegar às mães pobres via distribuição gratuita de leite feita pelo governo, sempre com o apoio dos profissionais da Saúde. Essa era uma forma de promover o uso do leite artificial, proporcionando o aumento de seu consumo ${ }^{24}$. Nesse sentido, as embalagens funcionavam como dimensão publicitária dos produtos, evidenciando que propaganda não se restringia aos anúncios explícitos, englobando várias dimensões de existência e circulação das mercadorias. Ela também se articulava a quadros de carência alimentar da população, atendendo a demandas que visavam superá-los.

A Literatura Médica, preocupada com índices de mortalidade infantil, dedicou-se a sugestões de práticas da saúde pública voltadas para resolver esses problemas. Através da escrita sobre a infância, ela teve nos textos a principal força de seus argumentos, concebendo a cultura letrada como privilegiada no sentido da intervenção social. Ao contrário da propaganda, que "popularizava" a linguagem, ela "sofisticava" suas mensagens, dirigindo-se a públicos especializados, dominando vocabulário técnico e científico; julgava-se mesmo dona do saber sobre os corpos. Foi 
argumento corrente no Brasil dos anos 30 a 50 que a criança precisava possuir corpo e mente sãos; daí a necessidade de investimentos em escolaridade, hábitos de leitura necessários para a formação do cidadão e da Nação saudáveis. Num país como o Brasil, onde os índices de analfabetismo tinham sido, até então, bastante elevados ${ }^{25}$, investir na infância, alfabetizando, seria corrigir vários desvios da Nação. Esses problemas apareceram em vários materiais da imprensa destinados à infância ou a ela relativos e a publicidade manteve-se articulada a tais preocupações.

Propagandas da Light investiam na imagem do sucesso escolar como dimensão fundamental do ser criança: a boa iluminação evitaria desgaste dos olhos e garantiria um bom aproveitamento na escola. Também nesse caso, o futuro da criança foi associado à atuação em profissões prestigiadas socialmente, como Medicina, Engenharia e Direito, convidando o leitor e usuário da Light a romper com a idéia de problemas de vista cansada pela hereditariedade, sugenindo que o ambiente bem iluminado poderia superar essa questão. A idéia da prevenção estava associada aos cuidados com a infância. Sintomas como dor de cabeça e cansaço foram associados à má iluminação, sendo casa e lugar de trabalho privilegiados para observar cuidados com a luminosidade. A produtividade máxima 264 em casa e no trabalho seriam, assim, garantidas pela iluminação adequada. Essa publicidade da Light também apelava para estatísticas e argumentos científicos como autoridades que comprovavam os argumentos. A má iluminação foi considerada inimiga do sucesso, tanto para o adulto como para a criança. No último caso, os desenhos apresentaram um ar pesado no ambiente e nas próprias figuras humanas, sendo o uso infantil de óculos tratado como algo indesejável, significando um envelhecimento precoce. Ao mesmo tempo, o argumento da necessidade da boa iluminação procurou atingir diferentes faixas etárias (crianças, jovens adultos, idosos) de ambos os sexos. As mulheres foram apresentadas costurando ou bordando, em casa, e fazendo compras, enquanto os homens figuraram em atividades profissionais, lendo jornais e livros.

Nesse contexto, o mundo moderno foi associado à prática da leitura e a outras atividades que requeriam maior uso da visão. O universo da compra e venda de mercadorias também foi vinculado à boa iluminação, por meio da valorização dos produtos, que atrairia mais e mais clientes. Por outro lado, a iluminação elétrica foi reiteradamente anunciada como barata, custando menos que uma barra de chocolate ou um cigarro e provocando prazer e benefícios mais duradouros ${ }^{26}$.

O tema da Infância saudável foi objeto de propagandas que anun- 
ciavam alimentos, como Toddy em Vida Doméstica, em dezembro de 1949, que destacou menino, vestido com blusa de mangas curtas xadrez, calças curtas, pulando cerca, em atitude de descontração e alegria. $O$ texto privilegiou vigor e energia, realçando o valor nutritivo daquele produto. Tais preocupações se fizeram presentes na revista Sesinho, que também divulgou em suas páginas concursos de robustez infantil, realizados em diversos Estados do Brasil, sendo membros das Comissões Julgadoras autoridades dos locais onde os certames eram efetivados - Prefeitos, Religiosos, pessoas ligadas à direção do SESI ${ }^{27}$.

As propagandas de eletrodomésticos também colocavam com freqüência a possibilidade de produzirem alimentos saudáveis para crianças, como em anúncio do liquidificador Walita publicado em $\mathrm{O}$ Estado de São Paulo de 15 de janeiro de 1950. Esse anúncio ampliou o campo da publicidade dos alimentos industrializados, introduzindo o eletrodoméstico como artefato produtor de alimentos em casa, signo da expansão do consumo de produtos industriais por setores sociais majoritários. Uma propaganda como essa do Liquidificador Walita circulava em diferentes veículos (revistas, jornais), sendo, às vezes, transferida mais explicitamente para outras linguagens. Foi o caso do "Ah!" do creme dental Kolynos, também presente em rádio e televisão. Isso colocava um espaço cultural da propaganda, oferecendo referenciais para o público em diferentes momentos e contextos. Anúncios mais explícitos sobre saúde infantil destacaram remédios contra diarréias, resfriados, eczemas, assaduras e câncer ${ }^{28}$.

Nas seções referentes à puericultura, a propaganda também apareceu, indicando caminhos para força e robustez infantis. Assim, foi anunciado em Vida Doméstica de março de 1948 um produto, Ferro Arsylose, contra fastio e anemia e para aumentar o peso, apresentando menino em cuecas, ereto, corpo esbelto, mãos na cintura. Noutro exemplo, figuraram menino e menina, voltados para placa onde se escreveu "Cálcio Baby", com a menina usando laço de fita na cabeça, segurando boneca negra e ambos de costas para o público leitor, enquanto o texto afirmava: "O recalcificante ideal para criança, à venda em todas as farmácias e drogarias". O primeiro exemplo associou a saúde a uma aparência física e, por tanto, a uma corporeidade. No outro caso, houve preocupação com maior abrangência de gênero, evidenciand o que o problema também dizia respeito às meninas.

Anúncio de xarope especialmente indicado para as crianças não o asso ciou à família, co mo em muitos outros casos; reclame do inseticida Flit usou como estratégia do convencimento a saúde infantil, dizendo que 
o produto combatia as moscas, responsáveis pela diarréia infantil, provocadoras da morte de $25 \%$ de crianças antes dos 5 anos, aconselhando seu extermínio para salvar as crianças e caracterizando o produto como "infalível contra moscas, mosquitos, traças, formigas, baratas e percevejos", ao mesmo tempo em que não fazia mal aos homens, afirmava Vida Do méstica em outubro de 1931. Essa situação articulou-se com um quadro do urbano no Brasil, entendido como ainda marcado por doenças transmissíveis, diferenciando-se de campanhas sanitárias públicas, como as de Oswaldo Cruz, no início do século XX, porque associada no novo momento a soluções do consumo privado, expresso na compra de produtos como aquele. A mortalidade infantil, portanto, foi tema reapropriado pela propaganda e devolvido na forma do consumo redentor de determinados produtos, como, dentre outros, Lysol e Johnson \& Johnson. Ao mesmo tempo, essa propaganda diluiu questões presentes noutros debates sobre 0 assunto, como condições de moradia e higiene pública, tornando o tema circunscrito ao espaço e à ação domésticos.

A imagem na propaganda do inseticida Flit explorou soldado de chumbo, símbolo do produto. No desenho, ele adquiriu movimento, espirrando grande e assustadora mosca. Em plano menor, duas crianças brincavam. O soldado, representando o produto, salvava, protegia, livrava as crianças do mal, da morte, permitindo que elas vivessem felizes, brincando, sem problemas. Esse é um tema recorrente em setores da literatura infantil, que explorava a dimensão heróica de certos personagens, opondo o Bem ao Mal, capazes de livrarem as crianças de infortúnios, demonstrando que a propaganda também dialogava com uma cultura referida às crianças, como era o caso daquela produção literária. A Cia. Ed. Melhoramentos marcou presença na cena publicitária anunciando a venda de brinquedos e livros infantis, indicando preços e realçando que "As crianças gostam desses presentes". A Casa Alemã, além de anunciar roupas infantis, também indicou brinquedos e bonecas, destacando qualidade e preços ${ }^{29}$.

Excetuando propagandas das publicações da Sociedade Gráfica Vida Doméstica, responsável por sua edição, Vida Infantil trabalhava bem menos com outros anúncios, que eram abundantes em Vida Doméstica. Quando novas publicidades apareceram na primeira revista, o tema de saúde e vigor surgiu como dimensão importante da infância ${ }^{30}$. Até na indicação de móveis para o consumo, como "poltrona cama", a saúde dos filhos era tema importante: "Seu filho deve dormir sozinho!". Esse anúncio continha desenho de mãe ajoelhada, cobrindo filho que dormia. A 
propaganda apresentou vários modelos de poltrona-cama e respectivos preços. O texto afirmou:

Os peritos de higiene infantil condenam o hábito de crianças dormirem com adultos ou mesmo com outras crianças. Cada qual deve ter seu leito individual. Até um canto da sala de jantar pode ser improvisado em dormitório dos meninos, pois, durante o dia, a Poltrona Cama Drago é um móvel útil e ornamental que se transforma facilmente, à noite, em sólido e confortável leito. Resolva de maneira prática e econômica um assunto de tão grande importância para a saúde de seus filhos, oferecendo-lhes leitos próprios, com as famosas Poltronas Camas Drago ${ }^{31}$.

Nesse caso, houve sugestão de público consumidor com padrão econômico apenas mediano ou até baixo, sem dormitónios individuais para os filhos, o que desdobrava aqueles outros argumentos da revista sobre luxo e sofisticação em modelos ideais de comportamento, adaptáveis a diferentes condições de vida. Além de saúde e praticidade, economia e beleza do produto foram apresentados como atrativos na propaganda. Usaram-se argumentos que sugeriram preocupações de cunho moral, apoiadas numa noção de privacidade que apelava para a autoridade de higiene e saúde. Tais padrões de moralidade, saúde e higiene, nesse caso, foram apresentados como válidos para todos os grupos sociais, articulando-se a debates sobre a questão da promiscuidade nos lares pobres em termos de adultos e crianças dormirem no mesmo ambiente.

Outra propaganda de Flit, em Vida Doméstica de outubro de 1931 não teve a criança co mo motivo, explorando várias dimensões da vida para convencer os consumidores. Mesmo nesse caso, a criança e seu bemestar foram fortes apelos para a compra do produto, sugerind o o quanto elas precisavam ser cuidadas. Dentre as possibilidades de males e doenças infantis que, naquela perspectiva, deviam ser combatidos, estavam 0 cansaço, o desânimo e a debilidade, que acabavam com o que deveria ser condição natural da infância - viço, alegria, força -, daí ser sugerido por Vida Doméstica em outubro de 1931 o uso de tônico infantil. A imagem de menina desanimada, braços caídos, cabeça baixa, em estado de prostração, mereceu a seguinte caracterização textual:

São três horas e já exausta! Muito cansada para fazer seus deveres e desanimada para brincar. Às três horas da tarde começa já a sentir-se nervosa irritável e exausta. Se continuar assim não terá chance na vida. Sua vitalidade, sua energia e seu estado de saúde, são minados com o veneno da eliminação incompleta. Um copo diário de ENO natural e seguro sal eferves- 
cente lhe devolveria a saúde. Seu médico concordaria porque ele sabe que o sal de Fruta Eno, atua suavemente e não contém drogas ou saes minerais que possam afetar o delicado organismo infantil ${ }^{32}$.

Essa criança surgiu como que condenada a tomar o produto diariamente para tornar-se disposta, calma e com possibilidades de vencer na vida. O saber médico foi utilizado para confirmar a necessidade do uso do medicamento. O corpo infantil, então, pareceu aprisionado pelo consumo de ENO, sugerindo comportamentos que nunca deviam sofrer alterações: era preciso estar sempre bem disposto, animado para o trabalho e lazer, tranqüilo. Esse produto estava associado ao consumo do adulto, possibilitando pensar sobre como, nesse período, práticas e discussões acerca do ser criança no so cial tinham pequena autonomia, sendo o infantil visto pela ótica do adulto que determinava como devia estar e o que usar. Os anúncios não trabalhavam a infância posicionando-se, intervindo, como se ela mesma quase nada tivesse a dizer. Naquele exemplo, um produto de consumo adulto foi orientado para uso infantil, o que significava tratar a criança como adulto e com remédio para adultos.

Na mesma direção de indicar remédios usados em comum por adultos e crianças, o anúncio de Candiolina Bayer em Vida Doméstica de outubro de 1927 apresentou o produto como uma espécie de bombom, gostoso e doce. Além da face curativa, esses anúncios de medicamento s e similares também trabalharam com a noção de prevenção, realçando ser este o caminho mais adequado para a preservação da saúde. Outra dimensão reforçada nesses anúncios foi a restrição desses tratamentos a poucas doses, capazes de garantirem a cura de diferentes males, como se observa em relação ao Vick-Vaporub. Isso também significou o diálogo entre produtos e campanhas, definindo as vantagens ou desvantagens dos diferentes produtos.

Anúncios de Cafiaspirina, para consumo de adultos, incluíram crianças no cotidiano dos consumidores, sugerindo a importância do medicamento para manter adultos sintonizados com certos rituais infantis - aprender a andar, nadar, etc. - , como se o remédio, por intermédio do bem-estar dos pais, fizesse parte daqueles momentos tão importantes. Produtos alimentares foram apresentados na condição de remédios fortificantes ou complementos alimentares, caso de Toddy, que tinha descrita sua composição - "vitaminas, carbohydratos, proteínas, ferro, fósforo e sais mi nerais" . Essa dimensão do Toddy como medicamente ou complemento alimentar apareceu até em propaganda de $1951^{33}$.

Essas questões se ampliaram nos anos 50 mas não foram exclusivas 
deles, apenas reapareceram de forma ampliada nessa década, considerando as novas possibilidades dos meios de comunicação que nasciam ou se expandiam. Outros setores industriais, como o de medicamentos ou higiene pessoal, também investiam intensamente no anúncio de seus produtos. Os cuidados com a saúde e higiene foram um tema recorrente no período indicado. Quando isto não ocorreu de maneira explícita, a imagem da infância remeteu para as idéias de graça, beleza e brincadeira, modalidades práticas daqueles valores. Nesse caso, a infância foi motivo para anunciar produtos que não se destinavam diretamente a ela.

Uma indústria importante na produção de artigos para higiene infantil foi a Johnson \& Johnson, implantada no Brasil em 1933, no bairro paulistano da Moóca e, depois, na cidade de São José dos Campos. Ela construiu uma auto-imagem apoiada em eficiência, qualidade, modemidade, permanente pesquisa, segurança, atenção para com seus funcionários - dimensões de publicidade da própria marca ${ }^{34}$. Uma estratégia publicitária da Johnson \& Johnson foi apresentar anúncio que se confundia com reportagem ou outra matéria editorial, usando fotografias e texto redigido como fala infantil, sucedido por outros que abordavam a condição materna, a presença do pai no cuidado com o filho e temas correlatos, sem uma apresentação direta dos seus produtos nas fotografias de crianças e pais sorridentes e descontraídos. Esse procedimento da fala infantil identificada à empresa anunciante ou ao seu produto também figurou em propaganda de liquidificador Arno, cujo texto inicial, associado à imagem de bebê rechonchudo e com um dedo na boca, foi: "Já estou com água na boca!" ${ }^{35}$.

Essas pequenas "reportagens" deram destaque textual aos produtos daquela marca, como talco e óleo, tendo sido divulgadas durante a Semana da Criança. Entre os temas presentes nos textos estava o aconselhamento na escolha de presentes por pais, outros parentes e mesmo amigos e vizinhos, evocando inclusive a importância de serem oferecidos às crianças pobres. Valores como desvelo dos pais, bom comportamento da criança, saúde desta e adequação dos produtos à delicadeza infantil foram explorados nesses materiais. A apresentação do pai como colaborador da mulher no banho da criança significou também um sintoma de modernidade em termos de divisão de tarefas e enfrentamento de dificuldades para contar com empregadas. Ao mesmo tempo, o material projetou para a criança bem cuidada futuro de sucesso profissional, em áreas como Medicina, Engenharia e Artes, identificando a infância ao futuro do pátria. Nem toda criança, evidentemente, trilharia esses caminhos de su- 
cesso, reservados a muito poucos. Nesse sentido, o discurso publicitário operava com fantasia em que o destino de poucos surgia legitimado como possibilidade para todos.

Esse apelo ao consumo de produtos para crianças em momentos como o Natal e a Semana da Criança assumiu a dimensão argumentativa de carinho e afeto, distribuída pontualmente, relacionando-se com determinados problemas (pobreza de uns, escasso relacionamento afetivo de outros) apenas naquelas ocasiõ es. O contato da propaganda com esse universo de problemas infantis foi marcado tanto pela imediatez - o evento comemorado - como pela continuidade de investimentos sobre a marca, feitos ao longo de anos ou mesmo décadas. Nesse sentido, a publicidade diferenciou-se de políticas públicas (parques infantis, creches) e outras iniciativas da sociedade civil (Cruzada Pró-Infância) no nível da imediatez de objetivos - o consumo puro e simples, no caso da publicidade mas também se articulou àquele universo por meio de valores como futuro da pátria e modernidade ${ }^{36}$.

Em diversas publicações, e não apenas nos anúncios, a casa foi apontada como lugar de tranqüilidade e aconchego, alheia a conflitos. Uma imagem veiculada em propaganda da Johnson \& Johnson, todavia, foi a 270 do lar como lugar perigoso ("Sua casa é o lugar mais perigoso do mundo"), caracterizando os produtos daquela marca como necessários nas emergências do cotidiano, dotados de uma especificidade curativa, de qualidades como maciez, pureza, absorvência, impermeabilidade e adesão instantânea à pele, oferecendo, ainda, como brinde para os interessados um Guia de Pronto-Socorro ${ }^{37}$. Uma preocupação fundamental nos anúncios do produto Band-Aid era a prevenção contra o risco de infecção. Nesses termos, os produtos da Johnson \& Johnson reafirmavam 0 cuidado com a saúde numa escala industrial, que significava ter recursos modernos e seguros à mão, dispensando o apelo permanente ao médico sem renunciar à voz da cientificidade. Algumas dessas peças publicitárias nessa revista até registravam choro, dor e tristeza das crianças devidos aos acidentes domésticos, situações conto madas e modificadas, todavia, pelo uso daqueles produtos. Band-Aid era caracterizado em propagandas como destinado ao uso de toda a família, sendo registrada sua aplicação em corpos de homens e mulheres adultos e crianças de ambos os sexos. Utilizando principalmente desenhos, essas publicidades ora recortaram partes feridas do corpo (dedos de mãos e pés, rosto, braço, calcanhar, joelho), ora apresentaram algumas de suas porções maiores - cabeça e tronco, por exemplo. Produto e publicidade estiveram ligados, 
portanto, aos cuidados com o corpo, situado numa dinâmica da vida moderna que se caracterizava por agilidade e uso adequado do tempo, interligando partes com aparência menor (uma bolha, um arranhão) ao todo da saúde, apoiando-se mesmo numa retórica do medo diante das potenciais ameaças representadas por aqueles pequenos acontecimento $\mathrm{S}^{38}$. Todas as figuras humanas apresentadas nessas propagandas do produto eram brancas e o próprio Band-Aid era fabricado num tom rosado claro, suposta cor da pele - branca, todavia... Isso se articula com a escassa presença de etnias não-brancas na publicidade, aqui desdobrada em pequena - ou nenhuma - produção destinada ao consumo desses grupos.

A linha de produtos infantis da Johnson \& Johnson englobava sabonete, óleo, creme, talco e fraldas. Sua publicidade impressa colocou mãe e filho como personagens permanentes, juntos, na maioria dos casos, ou apenas o último. A composição fotográfica trabalhou com blocos formados por mulher e criança, ora como uma espécie de "L" definido pelo corpo infantil deitado e o corpo da mãe que dele cuidava, prolongado na imagem do produto anunciado (talco), ora como círculo configurado pelo abraço da mãe no filho, com o corpo materno como uma espécie de alavanca, sustentando o nenê ou ainda com o tronco feminino estabelecendo paralelo com a embalagem de talco, produto mais anunciado nessa série - apenas uma dessas propagandas de SRD foi dedicada ao Óleo Johnson, apresentando um rosto de criança a chorar e, após a explicação para aquele estado ( "dor causada por pele irritada pela urina"), a indicação do referido produto. Qualidades indicadas nesses produto soram proteção, leveza, "conselho de médicos, maternidades, enfermeiras", suavidade, pureza, defesa contra irritações da pele infantil, delicadeza, geradoras de conforto para o bebê e tranqüilidade para a mãe.

A propaganda de Óleo e Talco Johnson \& Johnson apelou também para o diálogo entre mãe e bebê, com o último expressando a voz da empresa, demonstrando profundo conhecimento de seu próprio corpo, numa referência àquela marca como conhecedora dos corpos infantis. Essa argumentação estava sintonizada com uma linguagem médica sobre a especificidade do físico infantil, diferenciado do adulto, complexo, que exigia estudos, saberes e produtos apropriados. Tal propaganda se apoiou em situação ficcional, uma vez que bebês não falam, expressando desejos, necessidades e saberes diretamente relacionados ao consumo daqueles produtos. Ao mesmo tempo, a Johnson \& Jo hnson apareceu como orientadora e professora, assumindo o lugar do especialista que restaurava a saúde, a beleza e uma identidade angelical do bebê, como se obser- 
va especialmente no diálogo final entre os personagens: "Mamãe - Veja só! Cada dia que passa toda mamãe aprende uma coisa nova sobre os bebês. Bebê - Pois não há o que a Johnson não saiba sobre eles, mamãe! E logo que você fizer com que a minha pele fique novamente suave e gostosa, pode tratar de pregar as minhas asinhas bem aqui!" (a imagem apresentou criança apontando as costas) $)^{39}$.

As propagandas da Johnson \& Johnson exploravam sentimentos de amor e dedicação da mãe em relação ao filho, num vínculo de perfeita harmonia, interrompido ou abalado pelo choro da criança e restaurado pelo uso do produto. As imagens fotográficas utilizadas enfatizavam essa harmonia através de expressões faciais e corporais dos personagens, em situaçõ es de brincadeira e carinho da mãe em relação ao filho. Essas publicidades lançaram mão de uma retórica da desmedida, onde o uso de determinados produtos era caracterizado como solução para grandes problemas, como se observa no trecho: "Muitas vezes, o bebezinho chorão não tem culpa e bem desejaria atender ao apelo da voz materna... Mas sua pele delicada arde de brotoejas, que não o deixam dormir. Se isto ocorre com o seu bebê, mãezinha, aproveite a "Semana da Criança" para começar nova vida presenteando o seu filhinho com uma lata de talco 272 puro e um vidro de óleo especial para crianças" ${ }^{\prime 4}$.

As propagandas de produtos de beleza e higiene exploravam certo erotismo entre homem e mulher e apontavam possibilidades de sucesso nas relaçõ es afetivas para quem os usasse (ou fracasso para quem ainda não os utilizava), bem como sugeriam que a mulher estava ocupando novos espaços sociais (ambientes de trabalho, por exemplo). Aquele erotismo se manifestava como uso das imagens de pares, da proximidade entre seus corpos, do realce a detalhes corporais como boca e cabelos, aproximando-se de certa codificação presente na imagem cinematográfica, nos quadros da moralidade própria à época. Um erotismo indireto e mesmo sutil também foi esboçado mesmo ao redor de crianças, como em publicidade divulgada por O Cruzeiro, onde figuravam dois bebês de sexos diferentes: o menino olhava a menina e o balão acima dele continha a frase "Mas que bonitinha!", ao que ela respondeu: "Eu só uso Talco Johnson". Os corpos infantis - principalmente, quando bebês - eram os únicos que apareciam nus ou em trajes muito sumários (fraldas, por exemplo) naquelas situações, estabelecendo outros horizontes desse erotismo indireto.

Da mesma empresa, as escovas de dentes Tek tiveram realçadas a durabilidade, a eficácia, o uso por toda a família, ser preferida pela maio- 
ria. Slogans como "Dura, dura, dura" e "Siga a maioria" embasaram essas peças publicitárias, também associadas à beleza dos dentes que se desdobrava em beleza das pessoas, questão ainda articulada à sofisticação ${ }^{41}$.

A publicidade de Modess, da Johnson \& Johnson, trabalhou quase exclusivamente com a mulher adulta e a adolescente, destinatárias do produto. A criança figurou, todavia, como beneficiária do bem-estar que a adulta - mãe - desfrutava ao usar aquele artigo, num contexto de festa infantil em que se salientou a alegria da mulher, "mesmo naqueles dias" Nesses casos, utilizaram-se prioritariamente os argumentos de modernidade, conforto, higiene, orientação da filha adolescente, bem-estar, praticidade (produto descartável), além da distribuição de amostras grátis para leitoras que encaminhassem cupom preenchido com dados pessoais nome e endereço, o que mostra a associação entre imprensa e indústria.

Na perspectiva de trabalhar imagens idealizadas de mulher, a propaganda aproveitou valores significativos para a atuação feminina e os devolveu, aconselhando procedimentos. O "Regulador Gesteira", por exemplo, atuaria no sentido de evitar aborrecimentos, acalmar, tomando a mulher um sujeito bem-humorado, disposta para o trabalho doméstico, segundo o Fon-Fon de janeiro de 1938. O cotidiano do lar não era questionado em suas atividades estafantes, atribuía-se ao descontrole emocional o agravamento dos problemas. No mesmo sentido, problemas sociais mais amplos eram silenciados, com a publicidade apropriando-se de uma privacidade doméstica e feminina para realçar a facilidade da solução - 0 produto resolvia...

A insistência da propaganda em relação ao trabalho doméstico não deixou de apresentar novos horizontes para o universo feminino. A possibilidade de trabalho fora do lar foi apresentada em outras situaçõ es e mesmo a hipótese de se trabalhar como garota-propaganda foi explorada em artigo de revista, que destacou normas de contratação desse tipo de profissional, destacando a possibilidade de pessoas da família ou noivo da candidata acompanharem sessões de foto, numa atitude que sugeriu a confiabilidade nessa profissão, desfazendo possíveis comentários de que tal atividade não fosse coisa de família ${ }^{43}$.

A mulher foi também responsabilizada pela sua própria saúde, dos filhos e até do marido - saúde de toda a família, portanto - , observando cotidianamente o comportamento de todos e atuando como uma espécie de enfermeira do lar, aliada ao universo dos saberes modemos, dentre os quais, a propaganda. Havia certa assimetria na relação da mulher com 0 marido em situações de do ença: ele podia se irritar com os problemas da 
mulher mas o contrário não era legitimado, antes ocorrendo certa orientação para a mulher contribuir na cura dos males que afligiam o marido. Os anúncios, ao assumirem as mulheres como responsáveis pela saúde no lar, admitiam que os homens eram maus enfermeiros, acusando-as de imprudência quando adoeciam, sugerindo o que elas deviam evitar para não exporem os maridos a situações para as quais não estavam preparados.

A publicidade de revistas e jornais, portanto, permite refletir tanto sobre os temas que abordaram diretamente como também sobre problemas gerais: a saúde como valor fundamental, as expectativas (destinos que se desejava ou receava) reservadas para a infância, a configuração social de que esta fazia parte, a dimensão do conflito ${ }^{44}$. Diante dessas várias perspectivas publicitárias, cabe afirmar que tal campo não se reduziu à apresentação dos produtos, sendo também uma representação dos sujeitos que consumiam. Nesse sentido, a propaganda contribuiu de forma significativa para elaborar imagens de infância e família. Atuou, ainda, como elemento importante na elaboração daquilo que se desejava para o social, englobando elementos de exibição pública. No produto, por meio da publicidade, depositaram-se valores que expressaram desejos, configurando um destino identificado a "prazer" e "felicidade". Ao mes274 mo tempo, ela também pode ter criado frustrações em quem estava excluído do acesso ao consumo.

Essas aspirações e desejos foram além do imediatamente palpável, tanto do ângulo discursivo publicitário como do ponto de vista de quem consumia. Os produtos chegavam ao consumidor como alheios a um processo de trabalho na geração da mercadoria e de seu anúncio. Na propaganda, o novo era contraposto ao velho, superando-o, prometendo futuro de sucesso, sem renunciar a certa autoridade da tradição, capaz de legitimar determinados produtos. A propaganda também atuou no sentido de interferir em todas as dimensões do viver dos sujeitos, assumindo um caráter de um discurso to talizante (saúde, higiene pessoal, alimentação, lazer, vestimenta, escolaridade, habitação), estando sintonizada com outras propostas que cada período sugeria para o social. No entanto, na medida em que não se constituiu em mero reflexo de outras experiências, a propaganda construiu margens de autonomia, contribuindo para a formação de determinados hábitos e participando ativamente do imaginário social.

A posse de objetos na sociedade configurou-se como sintoma de poder e parte de outras relações: a corrente de ouro de uma moça mais abastada a diferenciava de uma empregada doméstica, que apenas usava 
uma tiara de plástico nos cabelos; a posse de uma máquina de lavar por uma favelada não se equiparava plenamente à mesma propriedade por uma senhora moradora de bairros nobres, inclusive porque a última devia contar com empregadas para manipular aquele objeto e tinha acesso a bens e serviços bastante diversificados (clubes, assistência médica privada, etc.), enquanto a outra punha sua máquina para funcionar depois de trabalhar noutros lugares. O acesso ampliado ao consumo, portanto, fazia parte da cultura de quem detinha certo nível de posses e de poder. Na cidade, esse processo atingiu seu máximo funcionamento: "O discurso da cidade é a própria concorrência: móveis, desejos, estímulos, erotização incessante, a informação, a solicitação publicitária (...), a concentração urbana suscita a eclosão ilimitada das necessidades" ${ }^{\prime 4}$.

No universo da publicidade brasileira dos anos 30 a 50 do século $\mathrm{XX}$, os usos da criança como justificativa ou destino da compra de mercadorias fez-se crescentemente presente, demonstrando como já se estava num mundo em que consumir foi transformado em viver desde a mais tenra infância.

\section{NOTAS}

${ }^{1}$ Um livro muito representativo desse campo político e cultural é: MARCUSE, Herbert. A Ideologia da Sociedade Industrial. Tradução de Giasone Rebuá. Rio de Janeiro, Zahar, 1979, (Atualidade).

${ }^{2}$ Fon-Fon! Rio de Janeiro, 20 abr. 1940. Daqui por diante, será citada no corpo do texto como FF.

${ }^{3}$ RAMOS, Ricardo. Do Reclame à Comunicação . São Paulo, Atual, 1987.

${ }^{4}$ SO DRÉ, Nelson Werneck. História da Imprensa no Brasil . 2 ${ }^{\underline{a}}$ ed., Rio de Janeiro, Graal, 1977. FIGUEIRED O, Anna Cristina Camargo Moraes. "Liberdade é uma Calça Velha, Azul e Desbotada" - Publicidade, Cultura de Consumo e Comportamento Político no Brasil (19541964) . São Paulo, HUCITEC/História Social-USP, 1998.

${ }^{5}$ Vida Doméstica. Rio de Janeiro, ago. 1938. Daqui por diante, será citada no corpo do texto como VD.

${ }^{6}$ TEMPORÃO, José Gomes. A Propaganda de Medicamentos e o Mito da Saúde . Rio de Janeiro, Graal, 1986. Esse Autor cita artigo do Dr. Galvão Flores, publicado na Revista Brasi leira de Medicina (Rio de Janeiro, 1947), exemplo expressivo das ressalvas médicas contra a propaganda popular de certos remédios - p. 31.

${ }^{7}$ CRESPO, Jorge. A História do Corpo. Lisboa/Rio de Janeiro, DIFEL/Bertrand Brasil, 1990, (Memória e Sociedade).

${ }^{8} \mathrm{Cf}$, a partir de outras fontes e temas: PAOLI, Maria Célia. Memória, História e Cidadania: $\mathrm{O}$ Direito ao Passado. In CUNHA, Maria Clementina Pereira (org.). O Direito à Memória - Pa trimônio Histórico e Cidadania . São Paulo, DPH/SMC, 1992, pp. 25-28.

${ }^{9}$ KLINTOWITZ, Jacob. Arte do Comércio. São Paulo, SESC, 1996. 
${ }^{10}$ Muitos exemplos da propaganda impressa brasileira do período aqui considerado foram reunidos na coletânea de reproduções fotográficas 100 anos de Pr opaganda , abrangendo desde fins do século XIX até o último quartel do século XX (anos 80), ajudando a localizar produtos, mercados consumidores, destinatários da mensagem (mulher como dona de casa) e diferentes tipos de imagens - fotografia, desenho, pintura. Da mesma forma, A Arte do Comércio trabalhou com fotografia, material que associou o crescimento da cidade à propaganda, com a preocupação de apresentar a visualidade da época e o design como artes plásticas. Essas duas publicações incluíram anúncios de vários jornais e revistas do Rio de Janeiro e de São Paulo, explorando muito a paisagem das cidades, seja através da propaganda ou da arquitetura, e oferecendo pistas para a pesquisa com fontes publicitárias. 100 Anos de Propaganda. São Paulo, Abril Cultural, 1980.

${ }^{11}$ CRUZ, Heloísa de Faria. Na Cidade, Sobre a Cidade - Cultura Letrada, Periodismo e Vi da Urbana - São Paulo, 1890/1915 . São Paulo, 1984. Tese (Doutoramento) - FFLCH/USP. Embora Cruz aborde período diferente do que é aqui trabalhado, suas reflexões transcendem rígidos limites cronológicos e ajudam a compreender procedimentos de Imprensa e Publicidade até meados so século XX.

${ }^{12}$ Sobre o Rio de Janeiro, ver: VELLOSO, Mônica Pimenta. Modernismo no Rio de Janeiro Turunas e Quixotes. Rio de Janeiro, Fundação Getúlio Vargas, 1996.

${ }^{13}$ Infância . São Paulo, fev. 1936 e Idem, fev. 1937. Daqui por diante, será citada no corpo do texto como I.

${ }^{14}$ SILVA, Marcos A. da. Prazer e Poder do Amigo da Onça . Rio de Janeiro, Paz e Terra, 1989. Figueiredo enfatizou tal expansão especialmente a partir de 1954, que escolheu como marco inicial de periodização (FIGUEIREDO).

${ }^{15}$ Linhas historiográficas a partir dos anos 70 criticaram tais argumentos modernizadores, analisando-os como estratégias de dominação: CHAUÍ, Marilena. "Apontamentos para uma Crítica da Ação Integralista Brasileira”. In CHAUÍ, Marilena e FRANCO, Maria Sylvia Carvalho. Ideologia e Mobilização Popular. Rio de Janeiro, Paz e Terra/CEDEC, 1978. DE DECCA, Edgar. 1930 - O Silêncio dos Vencidos. São Paulo, Brasiliense, 1981. MUNAKATA, Kazumi. A Legislação Trabalhista no Brasil . São Paulo, Brasiliense, 1981. ANTONACCI, Maria Antonieta M. Vitória da Razão? São Paulo, Marco Zero/CNPq, 1991.

${ }^{16}$ Nestlé: Setenta Anos de Brasil São Paulo, Assessoria de Imprensa da Nestlé, 1991. Nós So mos a Nestlé do Brasil. S/I/Local, S/I/Editora, S/Data. As propagandas aqui analisadas foram extraídas de cópias de Folhetos Publicitários da Nestlé, fornecidas pela empresa.

${ }^{17}$ Comentando a publicidade de cosméticos, Denise Sant'Anna assinalou que eles eram caracterizados como produtos de higiene e saúde até os anos 30, evidenciando a importância da saúde como fator para o consumo de diferentes produtos. SANT'ANNA, Denise Bemuzzi de. Cuidados de Si e Embelezamento Feminino: Fragmentos para uma História do Corpo no Brasil. In SANT'ANNA, Denise Bernuzzi de (org.). Políticas do Corpo. São Paulo, Estação Liberdade, 1997.

${ }^{18}$ Cópia de Folheto Publicitário da Nestlé, fornecida pela empresa, apenas com indicação do ano de publicação (1917).

${ }^{19}$ Situação diferente e mesmo oposta ocorreu quando Vida Doméstica e Fon-Fon! indicaram figurinos para homens, mulheres ou crianças, enfatizando a dimensão da roupa.

${ }^{20}$ Cópia de Folheto Publicitário da Nestlé, fornecida pela empresa, apenas com indicação do ano de publicação (1928). 
${ }^{21}$ Cópia de Folheto Publicitário da Nestlé, fornecida pela empresa, apenas com indicação do ano de publicação (1955).

${ }^{22}$ Cópia de Folheto Publicitário da Nestlé, fornecida pela empresa, apenas com indicação do ano de publicação (1961).

${ }^{23}$ Estudos sobre a proteção do recém-nascido contra o tétano umbilical pela imunização ativa da gestante em Anatoxina Tetânica . S/I/Local, S/I/Editora, 1953.

${ }^{24}$ REA, Marina Ferreira. "Substitutos do Leite Materno: Passado e Presente". In Revista de Saúde Pública . São Paulo, Faculdade de Saúde Pública, vol. 24, № 03, 1990, pp. 241-249.

${ }^{25}$ Beisiegel citou taxas de analfabetismo da população de 15 anos ou mais, que atestaram queda entre 1940 e 1960, com um percentual de 56,17 \% (1940), 50,48 (1950) e 39,35 (1960) daquele contingente. BEISIEGEL, Celso de Rui. "Educação e Sociedade no Brasil Após 1930". In FAUSTO, Boris (dir.). O Brasil Republicano (Economia e Cultura) . São Paulo, DIFEL, 1977, pp 381-416 (História Geral da Civilização Brasileira, tomo III, volume 10).

${ }^{26}$ Esse material sobre a Light foi obtido nos arquivos da Eletropaulo, que não possuem referências completas sobre parte dele: A Cidade. Itu, 20 jan. 1935. Correio Paulistano . São Paulo, 24 set. 1935. Correio de Sorocaba. Sorocaba, 3 fev. 1935. Cruzeir o do Sul. Sorocaba, 7 out. 1934. Diário da Noite. São Paulo, 3 jun. 1935. Diário Popular. São Paulo, 26 jan. 1935. Idem. 16 set. 1935. Diário de São Paulo . São Paulo, 15 set. 1935. O Estado de São Paulo. São Paulo, 14 ago. 1935. Idem. fev. 1935. Idem. 4 maio 1935. Idem. 19 maio 1935. Idem. 8 set. 1935. Fanfulla . São Paulo, 16 ago. 1935. Folha de Jundiaí. Jundiaí, 6 jan. 1935. Folha da Manhã . São Paulo, 11 jan. 1935. Idem. 10 jul. 1935. Folha da Noite. São Paulo, 26 dez. 1934. Folha do Povo. Jacareí, 13 jan. 1935. A Gazeta. São Paulo, 1ojul. 1938. Idem. set. 1935. O Liberal. Mogi das Cruzes, 20 jan. 1935. A Platéia. São Paulo, 11 maio 1935. O Povo. Salto, 27 jan. 1935.

${ }^{27}$ BRITES, Olga. Infância, Trabalho e Educação - A Revista 'Sesinho' . São Paulo, 1992. Dissertação (Mestrado) - PUC/SP.

${ }^{28}$ OESP, 8 jan. 1950. Idem, 12 jan. 1950. Idem, 20 jan. 1950. Idem, 21 jan. 1950. Idem, 14 fev. 1950.

${ }^{29}$ I, dez 1935 e dez 1936.

${ }^{30}$ É o caso do anúncio, já tantas vezes divulgado em outros veículos, do Biotônico Fontou$\mathrm{ra}$, destacando a energia gasta na infância com estudos e brincadeiras que precisava ser constantemente reposta, donde a eficácia atribuída àquele produto. Vida Infantil . Rio de Janeiro, no 33, jul. 1950.

${ }^{31} \mathrm{VD}$, jan. 1950.

${ }^{32} \mathrm{VD}, 19$ jul. 1941.

${ }^{33}$ VD, 15 out. 1932, abr. 1939 e fev. 1951.

${ }^{34}$ JOHNSON \& JOHNSON. “Uma Companhia a Serviço da Saúde e do Bem-Estar". S/I/Local, S/I/Editora, S/I/Data. No final da brochura, há síntese em inglês - "History of Johnson \& Johnson Brazil".

${ }^{35} \mathrm{VD}$, out. 1948 e mar. 1953.

${ }^{36}$ BRITES, Olga. Imagens da Infância - São Paulo e Rio de Janeiro, 1930 a 1950 . São Paulo, 1999. Tese (Doutoramento) - PUC/SP. 
${ }^{37}$ Seleções do Reader's DigestRio de Janeiro, nov. 1951. Doravante, citada no corpo do texto como SRD.

${ }^{38}$ SRD, mar. 1951, nov. 1953, abr. 1950, ago. 1950, jan. 1951, abr. 1951, jul. 1954, jul. 1953.

${ }^{39} \mathrm{VD}$, out. 1947.

${ }^{40} \mathrm{VD}$, out. 1949.

${ }^{41}$ SRD, abr. 1950; abr. 1951; jul. 1953; nov. 1953; jul. 1954.

${ }^{42}$ SRD, jul. 1953; abr. 1950; ago. 1950; jan. 1951; abr. 1951; nov. 1951; nov. 1953.

${ }^{43}$ Cigarra . Rio de Janeiro, jan. 1944. Em nome do trabalho feminino, certos medicamentos foram recomendados para atenderem às novas necessidades da mulher, anunciando que 0 organismo deve funcionar com precisão: "Hoje em dia, as mulheres concorrem com os homens nos mais diversos ramos de atividades: são caixeiras, datilógrafas, jornalistas e até aviadoras! Nessas condições, é indispensável que o organismo feminino funcione". VD, abr. 1939. Nessa perspectiva, para a mulher "funcionar bem" profissionalmente, ela devia ter uma relação de dependência com o remédio.

44 “Diga Isto ao seu Marido”. FF, mar 1942 e 03 de maio 1930. "Quando seu marido estiver sem apetite e se sentir indisposto ou adoentado, com empachamento, peso, dor e outros desarranjos do estômago, a língua suja, mau gosto na boca de manhã ou durante o dia, peso, calor e dor de cabeça, tonturas, nervosismo, certas co ceiras e irritaçõ es da pele, mal estar depois de comer, preguiça e moleza geral, dores, cólicas e outras perturbações do ventre, muita sede e quentura na garganta, ânsias e vontades de vomitar, mau hálito, indigestão, arrotos, gases diga-lhe que todos esses sofrimentos são causados por substâncias infectadas e fermentações tóxicas no estômago e intestinos e que use Ventre Livre sem demora."

${ }^{45}$ BAUDRILARD, Jean. A Sociedade de Consumo. Tradução de Artur Morão. Rio de Janeiro/Lisboa, Elfos/Edições 70, 1995 (Ciência e Sociedade - 3). 